\title{
Mechanistic Study of Hydroamination of Alkyne Through Tantalum-Based Silica-Supported Surface Species
}

\author{
Maha A. Aljuhani, ${ }^{a \S}$ Ziyun Zhang, ${ }^{\text {a }}$ Samir Barman, ${ }^{a \S}$ Mohamad El Eter, ${ }^{\text {a§ }}$ \\ Laura Failvene, ${ }^{\text {a }}$ Samy Ould-Chikh, ${ }^{\text {a§ }}$ Erjia Guan, ${ }^{\text {b+ }}$ EdyAbou-Hamad, ${ }^{\text {a+ }}$ Ab- \\ dul-Hamid Emwas, ${ }^{a+}$ Jérémie, DA Pelletier, ${ }^{a \S}$ Bruce C. Gates, ${ }^{b+*}$ Luigi \\ Cavallo, ${ }^{a s^{* *}}$ and Jean-Marie Basset. ${ }^{\text {a }}{ }^{* *}$
}

\author{
${ }^{a \S}$ KAUST Catalysis Center, Division of Physical Sciences and Engineering, King Abdullah University of Science and Tech- \\ nology (KAUST), Thuwal 23955-6900, Kingdom of Saudi Arabia \\ ${ }^{a+}$ King Abdullah University of Science and Technology (KAUST), Core Labs, Thuwal, 23955-6900, Kingdom of Saudi Ara- \\ bia \\ ${ }^{\mathrm{b}+}$ Department of Chemical Engineering, University of California, Davis, Davis, CA 95616, United States.
}

\section{Supporting Information Placeholder}

\begin{abstract}
Selective hydroamination of terminal alkynes with primary aryl amines is catalyzed by an unprecedented well-defined silica-supported tantalum complex $\left[(\equiv \mathrm{Si}-\mathrm{O}-) \mathrm{Ta}\left(\eta^{1} \sigma-\right.\right.$ $\left.\mathrm{NEtMe})_{2}\left(=\mathrm{N}^{t} \mathrm{Bu}\right)\right]$. A molecular-level characterization of the surface organometallic Ta species was done with the help of characterization techniques including as in situ infrared, in situ elemental microanalysis, ${ }^{1} \mathrm{H}$ and ${ }^{13} \mathrm{C}$ solid-state NMR (including double and triple quanta sequence), and X-ray absorption spectroscopies. These were complemented by the state-of-the-art DNP-SENS ${ }^{15} \mathrm{~N}$ characterization. Several catalytic intermediates have been isolated in particular the 4-membered metallacycle ring intermediate resulting from the Markovnikov addition of the alkyne to the surface tantalum imido. The mechanism proposed was based on the isolation of all intermediates. A DFT calculation has confirmed all the elementary steps and intermediates that were fully characterized.
\end{abstract}

Keywords: heterogeneous catalysis, hydroamination, SOMF, azametallacyclobutene, and imido fragment

Surface organometallic chemistry (SOMC) offers unique routes to prepare well-defined surface-supported metal fragments $(\mathrm{M}=\mathrm{C}, \mathrm{M}-\mathrm{C}, \mathrm{M}-\mathrm{H}, \mathrm{M}-\mathrm{NC} ; \mathrm{M}=$ metal $)$ and direct their reactivities toward targeted catalysis (e.g., alkane metathesis, alkene metathesis, methane non-oxidative coupling, ammonia synthesis, and Ziegler Natta depolymerization). ${ }^{1-5}$ Some ligands are key intermediates in several industrially important chemical processes such as alkane oxidation $(\mathrm{M}=\mathrm{O})^{3}$, alkene metathesis $\left(\mathrm{M}=\mathrm{CR}_{2}\right)^{4}$, and imine metathesis $(\mathrm{M}=\mathrm{NR}){ }^{6-7}$ Silica- supported metal imido complexes, in particular, have recently been shown to be efficient catalysts for imine metathesis. In this regard, molecular catalysts incorporating transition metals $(\mathrm{Zr} \text {, Hf, and Mo })^{6-8}$ have been investigated. Catalytic imine metathesis is assumed to be analogous to the alkene metathesis whereby two different imines afford a statistical mixture of all possible $=\mathrm{NR}$ exchange products in a $2+2$ cycloaddition fashion; most of the reported investigations, the metal center bearing an imido ligand $\mathrm{M}=\mathrm{NR}$ was found to be a prerequisite to achieve imine metathesis catalysis.

On the other hand, hydroamination is a reaction ${ }^{9-11}$ for which the $\mathrm{N}-\mathrm{H}$ bond is added across an unsaturated $\mathrm{C}=\mathrm{C}$ or $\mathrm{C} \equiv \mathrm{C}$ bond to lead to the formation of a range of organic molecules incorporating imines, enamine functionalities, and $\mathrm{N}$-containing heterocycles. ${ }^{12-}$ ${ }^{14}$ This atom economical process has been extensively over the preceding have been done with homogeneous catalysts incorporating metals with amido or imido ligand. ${ }^{15-16}$ This sort of nucleophilic addition reaction of unsaturated substrates is essential for the assembly of a wide variety of natural products, agrochemicals, pharmaceuticals and key intermediates in a number of industrial processes.

Notwithstanding the importance of this reaction, only a few supported catalysts have been explored. ${ }^{17-19}$ Our goals in the work described here were to investigate the scope of this reaction with a well-defined supported catalyst - a single-site tantalum complex grafted on silica. The supported tantalum complex, [( $\equiv \mathrm{Si}-\mathrm{O}-$ ) $\left.\mathrm{Ta}\left(\eta^{1} \sigma-\mathrm{NEtMe}\right)_{2}\left(=\mathrm{N}^{t} \mathrm{Bu}\right)\right]$, was chosen because it has been investigated for hydroamination of alkynes, and mechanistically its action is hypothesized to be related to the imine metathesis, as has been observed for silica-supported $\mathrm{Zr},{ }^{20} \mathrm{Mo},{ }^{6}$ and $\mathrm{Hf}^{8}$ imido complexes, whereby the metal-imido fragment serves as the key reaction site.

To prepare the desired tantalum complex on silica, a partially dehyroxylated silica $\left(\mathrm{SiO}_{2-700}\right)$ was treated with slight excess of the tantalum precursor complex $\left[\mathrm{Ta}\left(\eta^{1} \sigma-\mathrm{NEtMe}\right)_{3}\left(=\mathrm{N}^{t} \mathrm{Bu}\right)\right]$ in pentane at room temperature for $1 \mathrm{~h}$ (see the Supporting Information, SI, for experimental details). After repeated washing with pentane, followed by evacuation of the volatiles under dynamic vacuum $\left(10^{-5}\right.$ mbar), the supported complex 1 was obtained as a white powder. Comparison of the infrared (IR) spectra of $\mathbf{1}$ with that of pristine silica $\mathrm{SiO}_{2-700}$ revealed a nearly complete consumption of isolated silanols as evidenced by a sharp disappearance of the $v(\equiv \mathrm{SiO}-\mathrm{H})$ band at $3747 \mathrm{~cm}^{-1}$ (Figure 1). Simultaneously, two series of bands appeared at $2800-3000 \mathrm{~cm}^{-1}$ and at $1300-1500 \mathrm{~cm}^{-1}$ accounting, respectively, for $v_{(\mathrm{C}-\mathrm{H})}$ and $\delta_{(\mathrm{C}-\mathrm{H})}$ bands of alkyl moieties.

The grafting of $\left[\mathrm{Ta}\left(\eta^{1} \sigma-\mathrm{NEtMe}\right)_{3}\left(=\mathrm{N}^{t} \mathrm{Bu}\right)\right]$ species was further supported by the elemental analysis data giving a tantalum loading of $5.24 \mathrm{wt} \%$, which corresponds to $0.290 \mathrm{mmol} \mathrm{g}^{-1}$ and is in good agreement with the expected (theoretical) loading of $0.30 \mathrm{mmol}$ $\left.\mathrm{g}^{-1}\right){ }^{21}$ The contents of nitrogen content $\left(1.23 \mathrm{wt} \%, 0.88 \mathrm{mmol} \mathrm{g}^{-1}\right.$ of $\left.\mathrm{SiO}_{2-700}\right)$ and of carbon $\left(3.78 \mathrm{wt} \%, 3.16 \mathrm{mmol} \mathrm{g}^{-1}\right.$ of $\left.\mathrm{SiO}_{2-700}\right)$ with a N/Ta ratio of 3.04 and a C/Ta ratio of 10.90 in $\mathbf{1}$ are also in agreement with the expected values of 3.0 and 10.0, respectively, for a monopodal surface complex. 


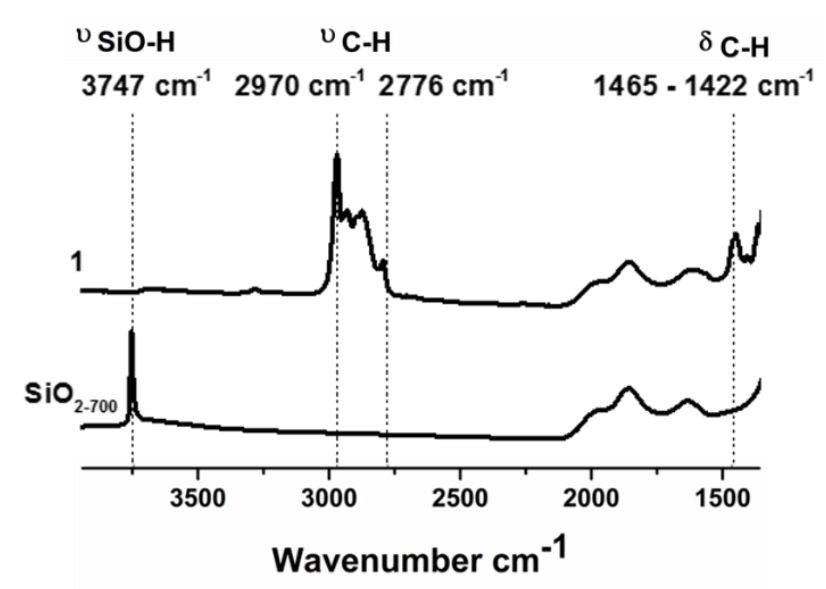

Figure 1. IR spectrum of $\mathrm{SiO}_{2-700}$ (bottom) and the grafted material $\left[(\equiv \mathrm{Si}-\mathrm{O}-) \mathrm{Ta}\left(\eta^{1} \sigma-\mathrm{NEtMe}\right)_{2}(=\mathrm{NtBu})\right](\mathbf{1})$.

Thus, we infer that the formulation of $\mathbf{1}$ as $\left[(\equiv \mathrm{Si}-\mathrm{O}-) \mathrm{Ta}\left(\eta^{1} \sigma-\right.\right.$ $\left.\mathrm{NEtMe})_{2}(=\mathrm{NtBu})\right]$ represents the data.

Further characterization of the supported species by ${ }^{1} \mathrm{H}$ and ${ }^{13} \mathrm{C}$ SS NMR spectroscopy supports the inference. Thus, in the ${ }^{1} \mathrm{H}$ MAS NMR spectrum, broad peaks at $1.1 \mathrm{ppm}$ are attributed to the methyl groups, with those at 2.3 and $3.1 \mathrm{ppm}$ are attributed to the various methylene protons. As expected, the two-dimensional proton double-quantum (DQ) experiments gave evidence of strongly correlated peaks for these signals, appearing at about 2.2, 4.6, and 6.3 $\mathrm{ppm}$ in the $\omega 1$ dimensions, respectively. The triple-quantum (TQ) spectra show a correlation peak, for the signal at $1.1 \mathrm{ppm}$, appearing at about $3.3 \mathrm{ppm}$ in the $\omega 1$ dimensions, thus indicative of the methyl protons. An additional correlation peak for the signal at 2.3 ppm in DQ is attributed to the proton of the $-\mathrm{CH}_{2}$ groups of the $\mathrm{NMeEt}$ ligands. In the ${ }^{13} \mathrm{C}$ MAS NMR spectra, eight peaks can be identified (at 12, 14, 32, 40, 43, 47, 52, and $65 \mathrm{ppm}$ ) (Figure 2). The ${ }^{13} \mathrm{C}$ signal at $65 \mathrm{ppm}$ likely originates from the quaternary carbon of the $t$-Bu group, and the strong peak at $32 \mathrm{ppm}$ is assigned to the corresponding methyl group of the $t$-Bu functionality. Among the remaining resonances, four ${ }^{13} \mathrm{C}$ signals between 40 and $52 \mathrm{ppm}$ are attributed to the carbons of the methylene groups of the $-\mathrm{N}(\mathrm{Me})($ $\mathrm{CH}_{2} \mathrm{Me}$ ) ligands. Further, the signals at 12 and 14 ppm can be assigned to the methyl of the $-\mathrm{N}(\mathrm{Me})\left(\mathrm{CH}_{2} \mathrm{Me}\right)$ ligands.

A HETCOR spectrum further allowed us to observe the correlation between the proton and the carbon signals. The peaks at 12, 14 , and $32 \mathrm{ppm}$ are correlated with that at $1.1 \mathrm{ppm}$ in the ${ }^{1} \mathrm{H}$ spectrum, strongly supporting the assignment of methyl of either $\mathrm{N}(\mathrm{Me})\left(\mathrm{CH}_{2} \mathrm{Me}\right)$ or $-\mathrm{NC}\left(\mathrm{CH}_{3}\right)_{3}$. The other signals, at $40,43,47$, and $52 \mathrm{ppm}$, appear to correlate with the resonance at 3.1 and $2.3 \mathrm{ppm}$, indicating that each can be attributed to the methylene of $\mathrm{N}(\mathrm{Me})\left(\mathrm{CH}_{2} \mathrm{Me}\right)$.
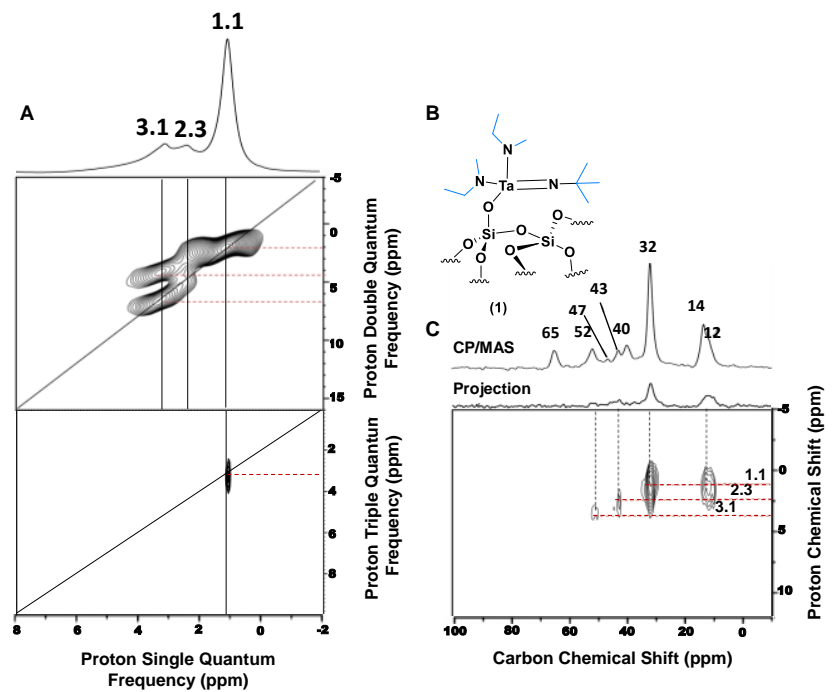

Figure 2. A) ${ }^{1} \mathrm{H}-{ }^{1} \mathrm{H}$ DQ $2 \mathrm{D}$ and TQ spectra; B), ${ }^{1} \mathrm{H}-{ }^{13} \mathrm{C}$ HETCOR NMR spectra of $\left[(\equiv \mathrm{Si}-\mathrm{O}-) \mathrm{Ta}\left(\eta^{1} \sigma-\mathrm{NEtMe}\right)_{2}\left(=\mathrm{N}^{\mathrm{t} B u}\right)\right], \mathbf{1}$; and $\left.\mathrm{C}\right)$, proposed structure of $\mathbf{1}$.

The ${ }^{15} \mathrm{~N}$ DNP_SENS spectra of $\mathbf{1}$ (Figure 3 ) include signals at 14,43 , and $163 \mathrm{ppm}$; the signal that is downfield-shifted the most, at $163 \mathrm{ppm}$, likely originates from the imido fragment, with the other two signals presumably indicative of the different orientations of nitrogen of the -NMeEt groups. Prediction of the $\mathrm{N}$ magnetic shielding via DFT calculations on a Ta complex representative of 1 was performed to support this conclusion. Consistently with the experimental findings, we found that the signal of the imido nitrogen is shifted more than $100 \mathrm{ppm}$ downfield relative to the signals of the two amine fragments (see Table S2).

The ${ }^{1} \mathrm{H}_{-}{ }^{15} \mathrm{~N}$ HETCOR DNP NMR spectrum shows only one nitrogen peak correlated with one proton type, which is $-\mathrm{CH}_{3}$ (Figure S4 in the SI).

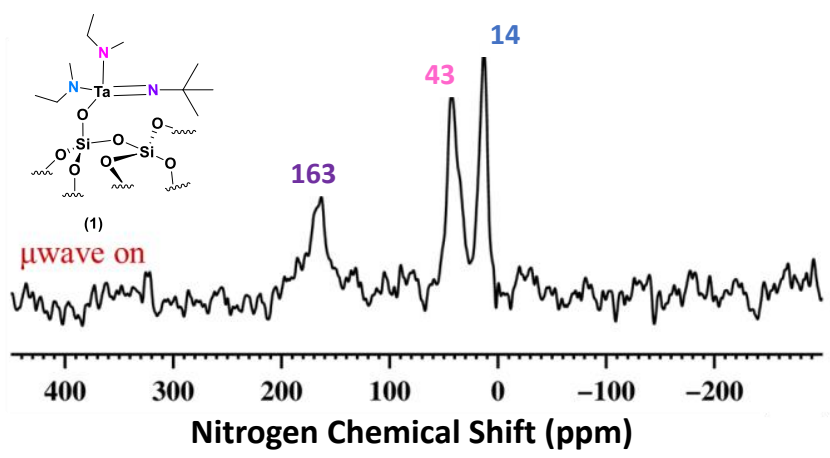

Figure 3. ${ }^{15} \mathrm{~N}$ DNP-SENS of $\left[(\equiv \mathrm{Si}-\mathrm{O}-) \mathrm{Ta}\left(\eta^{1} \sigma-\mathrm{NEtMe}\right)_{2}\left(=\mathrm{N}^{\mathrm{t} B u}\right)\right] \mathbf{1}$.

To provide supplementary structural characterization of the supported Ta complex, we recorded X-ray absorption spectra, including extended X-ray absorption fine structure (EXAFS) spectra at the Ta LiII edge, with the sample in an argon atmosphere at room temperature. We stress that this technique is not sufficient to distinguish the light backscatterers $\mathrm{O}$ and $\mathrm{N}$ from each other or to identify and determine the coordination numbers of all the atoms in the 
near neighborhood of the Ta atom (because the structure is too complex). To be able to do the data fitting, we had to introduce constraints to simplify the analysis: because we could not distinguish Ta-light backscatterer contributions, we constrained the disorder terms for these contributions to be the same, and, further, we constrained the coordination numbers according to the structure stated above for 1 (Figure 4). The value of the X-ray absorption spectra is that they confirm the presence of Ta in the sample (by the observed absorption at the Ta LIII edge) and are consistent with the structural model of $\mathbf{1}$ determined from the other data, providing estimates of interatomic distances.

Thus, a good fit of the data was found (Figure 4, Table 1), with one $\mathrm{Ta}-\mathrm{C}(\mathrm{Ta}=\mathrm{N}-\mathrm{C})$ contribution, at a distance of $3.30 \AA$, with two multiple-scattering paths, Ta-C-N and $\mathrm{Ta}-\mathrm{N}-\mathrm{C}-\mathrm{N}$, considered, because these are characteristic of a linear $\mathrm{Ta}=\mathrm{N}-\mathrm{C}$ moiety (the parameters of the multiple scattering paths were constrained with the $\mathrm{Ta}-\mathrm{C}(\mathrm{Ta}=\mathrm{N}-\mathrm{C})$ single scattering parameters. In the fitting, three $\mathrm{Ta}-\mathrm{C}$ contributions were found, with a total coordination number $\mathrm{CN}$ of 4 , at distances of $2.94,3.00$, and $3.14 \AA$, representing $\mathrm{C}$ atoms in the organic ligands. Given the aforementioned limitations of the analysis, we infer that the fitting results are in satisfactory agreement with the structure shown in Figure 4 (inset). Two Ta-N contributions, with coordination numbers of 1.0 and 2.1, were found at distances of 1.78 and $1.97 \AA$, respectively, consistent with the inference that one $\mathrm{N}$ atom is double bonded and two are single bonded to $\mathrm{Ta}$. One $\mathrm{Ta}-\mathrm{O}$ contribution with a coordination number of 1.4 was found at a distance of $1.92 \AA$, consistent with the inference that Ta was chemically bonded to support oxygen (Table 1), but this value was not determined with sufficient accuracy to determine the podality of the complex. Details are stated in the SI.

Table 1. EXAFS structure parameters a representing the supported tantalum complex

\begin{tabular}{|c|c|c|c|c|c|}
\hline Shell & $N$ & $\begin{array}{l}\mathbf{R} \\
(\AA)\end{array}$ & $\begin{array}{r}10^{3} \times \\
\Delta \sigma^{2}(\AA)\end{array}$ & $\underset{(\mathrm{eV})}{\Delta E_{0}}$ & $\begin{array}{c}\text { R- } \\
\text { Factor }\end{array}$ \\
\hline $\mathrm{Ta}=\mathrm{N}_{1}$ & 1.0 & 1.78 & 1.9 & 5.77 & 0.0077 \\
\hline $\mathrm{Ta}-\mathrm{O}_{\mathrm{s}}$ & 1.4 & 1.92 & 2.4 & & \\
\hline $\mathrm{Ta}-\mathrm{N}_{2}$ & 2.1 & 1.97 & 1.6 & & \\
\hline $\mathrm{Ta}-\mathrm{C}_{1}$ & 1.1 & 2.94 & 12.2 & & \\
\hline $\mathrm{Ta}-\mathrm{C}_{2}$ & 1.1 & 3.00 & 12.2 & & \\
\hline $\mathrm{Ta}-\mathrm{C}_{3}$ & 2.2 & 3.14 & 12.2 & & \\
\hline $\mathrm{Ta}=\mathrm{N}-\mathrm{C}^{\mathrm{b}}$ & 1 & 3.30 & 4.7 & & \\
\hline
\end{tabular}

a Notation: $N$, coordination number; $R$, distance between absorber and backscatterer atoms; $\Delta \boldsymbol{\sigma}^{2}$, disorder term; $\Delta E_{\mathbf{0}}$, inner potential correction; $k$ range: $3.7-12 \AA^{-1} ; R$ range: $1.1-3.6 \AA .{ }^{\mathrm{b}}$ multiple scattering paths were considered and the parameters are constrained; details are stated in the SI.
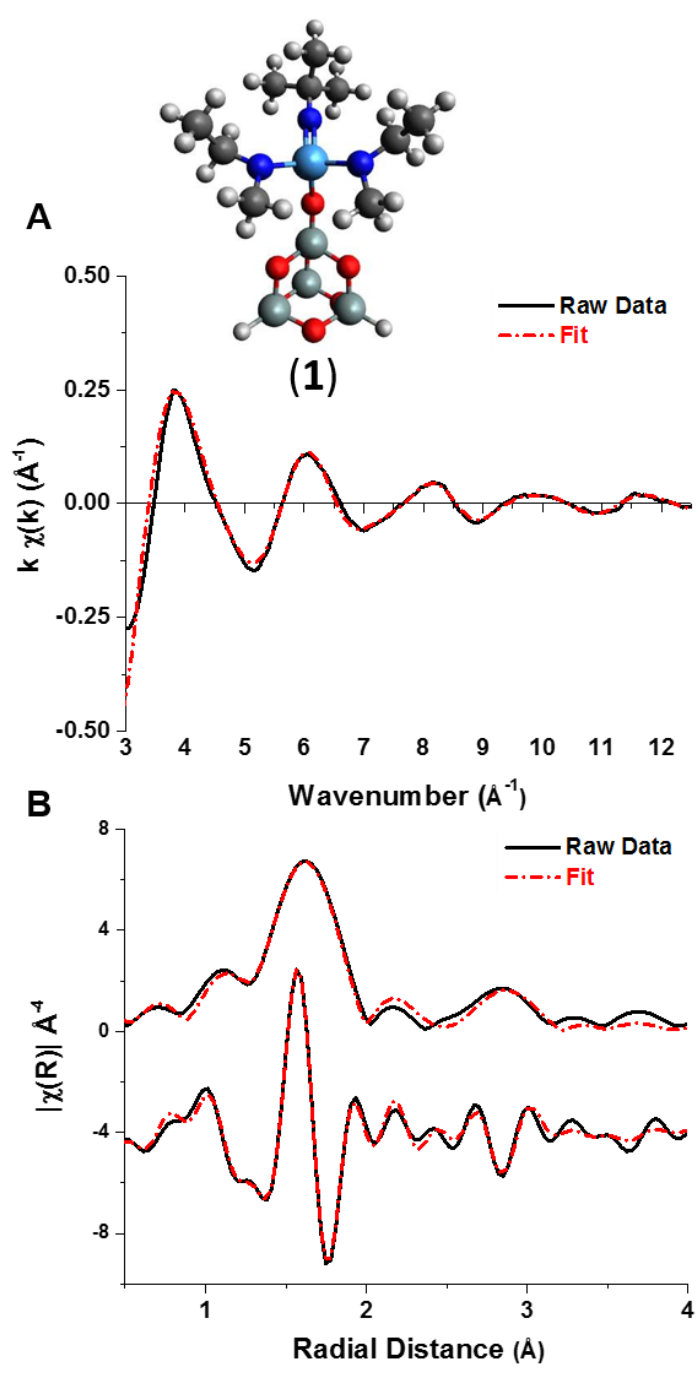

Figure 4. A) (Inset) Structure of Ta complex as a reference for EXAFS modeling and EXAFS data characterizing the tantalum complex: $k^{1}$-weighted EXAFS function ( $k$ is the wave function), $k^{1}(\chi)$ (solid line), and sum of the calculated contributions (dashed line). B) $k^{3}$-Weighted imaginary part and magnitude of the Fourier transform of the EXAFS data (solid line) and sum of the calculated contributions (dashed line) of the samples represented in (Table 1).

Before evaluating the reactivity of $\mathbf{1}$ in the hydroamination reaction, we strived to isolate and characterize various intermediate species which were expected to form during the catalytic reaction. To begin, 1 was treated in a batch reactor with 1 -octyne at $80^{\circ} \mathrm{C}$ for $16 \mathrm{~h}$, resulting in species 2 after washing with pentane and evacuation under dynamic vacuum. In the next experiment, $\mathbf{1}$ was allowed to react with the primary aryl amine aniline, and after washing and vacuum treatment, species $\mathbf{3}$ formed. Both $\mathbf{2}$ and $\mathbf{3}$ were then thoroughly examined by IR spectroscopy, elemental analysis, and SS NMR spectroscopy (see SI Figure S2 for IR data and Figures 5-8 for NMR spectra).

As depicted in Figure 5, the 1D ${ }^{1} \mathrm{H}$ spectra showed slightly altered spectral features relative to the parent species $\mathbf{1}$, showing two sets of broad signals centered at about 1.6 and $2.7 \mathrm{ppm}$ and attributable to the various methyl and methylene protons, respectively. These assignments evidently agree with the results obtained from 
the two-dimensional proton DQ and TQ correlation experiments, which gave evidence of strong correlation peaks (for the $1.6 \mathrm{ppm}$ signal at about $3.1 \mathrm{ppm}$ and $6.3 \mathrm{ppm}$ in the $\omega 1$ dimensions, respectively), indicative of methyl protons. Notably for the $1 \mathrm{D}{ }^{1} \mathrm{H}$ peak at $2.7 \mathrm{ppm}$ we observed a correlation signal only in the DQ spectra (at $5.4 \mathrm{ppm}$ in the $\omega 1$ dimensions) but not in the TQ spectra, thus affirming its methylenic nature. The ${ }^{13} \mathrm{C}$ MAS NMR spectrum of 2 (Figure 5) displays broad signals at 11, 32, 43, and $65 \mathrm{ppm}$, which were present in the parent species 1 . However, significantly, we found a set of ${ }^{13} \mathrm{C}$ signals at approximately 22 and $29 \mathrm{ppm}$ ascribable to the methyl and methylene carbon of the incoming alkyne molecule. Those assignments were further corroborated by the ${ }^{1} \mathrm{H}-$ ${ }^{13} \mathrm{C}$ HETCOR NMR spectroscopic analysis, which shows clearly identifiable correlation signals with the ${ }^{1} \mathrm{H}$ signal at $1.6 \mathrm{ppm}$.

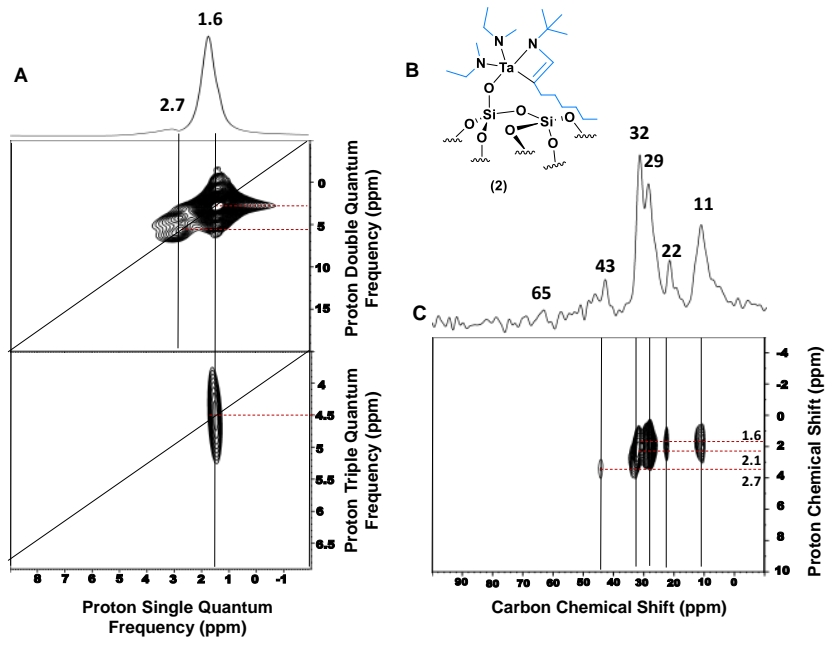

Figure 5. A) ${ }^{1} \mathrm{H}-\mathrm{NMR},{ }^{1} \mathrm{H}-{ }^{1} \mathrm{H}$ DQ spectra $2 \mathrm{D}$ and TQ B), proposed structure of 2, [( $\left.\equiv \mathrm{Si}-\mathrm{O}-) \mathrm{Ta}\left(\eta^{1} \sigma-\mathrm{NEtMe}\right)_{2}\left(\eta^{2} \mathrm{~N}^{\mathrm{t}} \mathrm{BuCH}=\mathrm{C}_{7} \mathrm{H}_{13}\right)\right]$ and C), CP/MAS and HETCOR NMR spectra of 2.

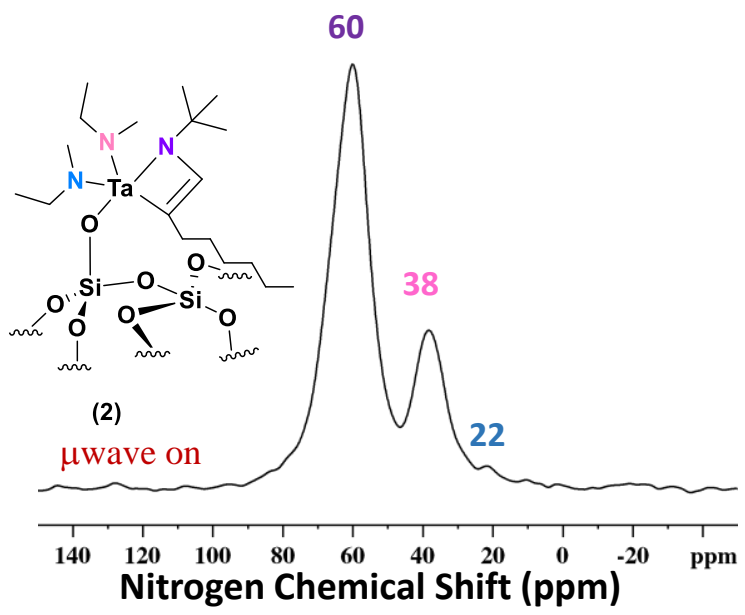

Figure $\quad 6 .{ }^{15} \mathrm{~N} \quad$ DNP-SENS of $\quad\left[(\equiv \mathrm{Si}-\mathrm{O}-) \mathrm{Ta}\left(\eta^{1} \sigma-\right.\right.$ $\left.\mathrm{NEtMe})_{2}\left(\eta^{2} \mathrm{~N}^{t} \mathrm{BuCH}=\mathrm{C}_{7} \mathrm{H}_{13}\right)\right] 2$.
More importantly, the ${ }^{15} \mathrm{~N}$ DNP-SENS (Figure 6) spectrum of 2 displays no signal (expected in the range of 150-165 ppm) corresponding to the imido fragment that was observed in the spectrum of 1 . In contrast, a significantly altered ${ }^{15} \mathrm{~N}$ NMR spectral feature was observed. Thus, the chemical shift of the ${ }^{15} \mathrm{~N}$ signals were observed at 22, 38, and $60 \mathrm{ppm}$ (Figure 6). The upfield-shifted signals are likely to originate (as in 1) from the nitrogen of the $\mathrm{N}(\mathrm{Me})\left(\mathrm{CH}_{2} \mathrm{Me}\right)$ groups present in different orientations. The ${ }^{15} \mathrm{~N}$ signal at $60 \mathrm{ppm}$ correlates with the ${ }^{1} \mathrm{H}$ signal at $1.6 \mathrm{ppm}$ in the ${ }^{1} \mathrm{H}-$ ${ }^{15} \mathrm{~N}$ HETCOR DNP NMR spectra (Figure S5 in the SI)). It very likely originates from the imido fragment after undergoing a $2+2$ cycloaddition reaction with the incoming alkyne molecule. Prediction of the $\mathrm{N}$ magnetic shielding via DFT calculations on Ta complexes representative of the mentioned metallacycle species from Markovnikov and anti-Markovnikov cycloaddition was performed to further rationalize the experimental results. The three $\mathrm{N}$ magnetic shieldings for complex 2 resulting from anti-Markovnikov cycloaddition correlate with the experimental signals better than those resulting from Markovnikov cycloaddition $\left(\mathrm{R}^{2}=0.99\right.$ vs. $\left.\mathrm{R}^{2}=0.72\right)$, supporting the anti-Markovnikov regioselectivity of cycloaddition during the initiation step (see Table S3). This conclusion is consistent with the DFT modeled reactivity, see Figure S12 and related discussion.

The solid-state NMR data characterizing 3 indicate incorporation of incoming amine substrate in $\mathbf{1}$ by the appearance of additional ${ }^{1} \mathrm{H}$ and ${ }^{13} \mathrm{C}$ NMR signals (apart from those observed in 1) corresponding to the aromatic functional groups (Figure 7). This result was further confirmed by the $2 \mathrm{D}{ }^{1} \mathrm{H}-{ }^{1} \mathrm{H}$ DQ, TQ and ${ }^{1} \mathrm{H}-{ }^{13} \mathrm{C}$ HETCOR NMR signals at 2.2 and $2.6 \mathrm{ppm}$ assigned to the methylene group and in TQ at 1.0 and $0.8 \mathrm{ppm}$ assigned to the methyl groups of the $\mathrm{N}(\mathrm{Me})\left(\mathrm{CH}_{2} \mathrm{Me}\right)$ and $\mathrm{NH}-t$-Bu groups. The signals at 2.6 and $2.2 \mathrm{ppm}$ represent the $-\mathrm{CH}_{2}$ protons in $-\mathrm{N}(\mathrm{Me})\left(\mathrm{CH}_{2} \mathrm{Me}\right)$ groups. The correlation between the protons and the carbons in HETCOR shows that the signal at $65 \mathrm{ppm}$ is consistent with that of a quaternary carbon and the methyl of the $t$-Bu ligand, and the signals at 32 and $29 \mathrm{ppm}$ are evidence of the methyl groups of the $t$ $\mathrm{Bu}$ and $-\mathrm{NmeEt}$ groups. The resonances at about $46 \mathrm{ppm}$ are consistent with a carbon of the methylene from the $-\mathrm{N}(\mathrm{Me})\left(\mathrm{CH}_{2} \mathrm{Me}\right)$ ligands. The signal of $11 \mathrm{ppm}$ can be assigned to the methyl from the $-\mathrm{N}(\mathrm{Me})\left(\mathrm{CH}_{2} \mathrm{Me}\right)$ ligands. Further, the signals at 118 and 130 ppm are correlated with that at $6.9 \mathrm{ppm}$ in the ${ }^{1} \mathrm{H}$ spectrum, indicating the aromatic rings of $-\mathrm{NH}\left(\mathrm{C}_{6} \mathrm{H}_{5}\right)$, and that at $147 \mathrm{ppm}$ represents the quaternary carbon in aniline (Figure 7). More significantly, the ${ }^{15} \mathrm{~N}$ DNP_SENS data further allow us to infer that the reaction of aniline occurred at the imido center via proton transfer, resulting in the disappearance of the ${ }^{15} \mathrm{~N}$ signal at $163 \mathrm{ppm}$ (observed in 1); the appearance of new signals at 50 and $78 \mathrm{ppm}$ is ascribed to the newly generated ${ }^{15} \mathrm{~N}$ sites (Figure 8 and Figure S6 in the SI). 


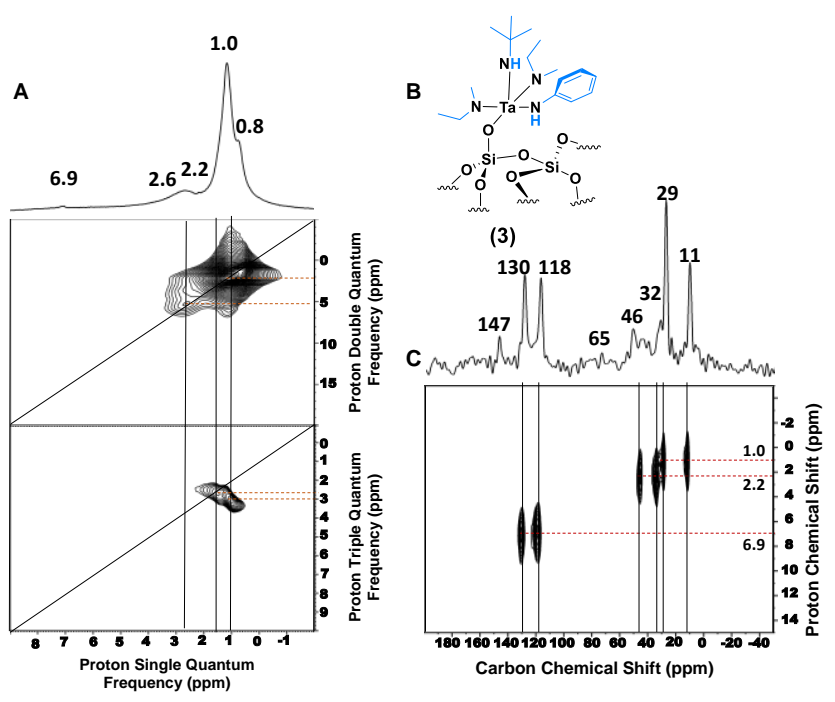

Figure 7. A) ${ }^{1} \mathrm{H}-\mathrm{NMR},{ }^{1} \mathrm{H}-{ }^{1} \mathrm{H}$ DQ $2 \mathrm{D}$ and TQ spectra B), proposed structure of $3\left[(\equiv \mathrm{Si}-\mathrm{O}-) \mathrm{Ta}\left(\eta^{1} \sigma-\mathrm{NEtMe}\right)_{2}\left(-\mathrm{NH}^{\mathrm{t}} \mathrm{Bu}\right)\left(-\mathrm{NHC}_{6} \mathrm{H}_{5}\right]\right.$ and C), CP/MAS and HETCOR NMR spectra of $\mathbf{3}$.

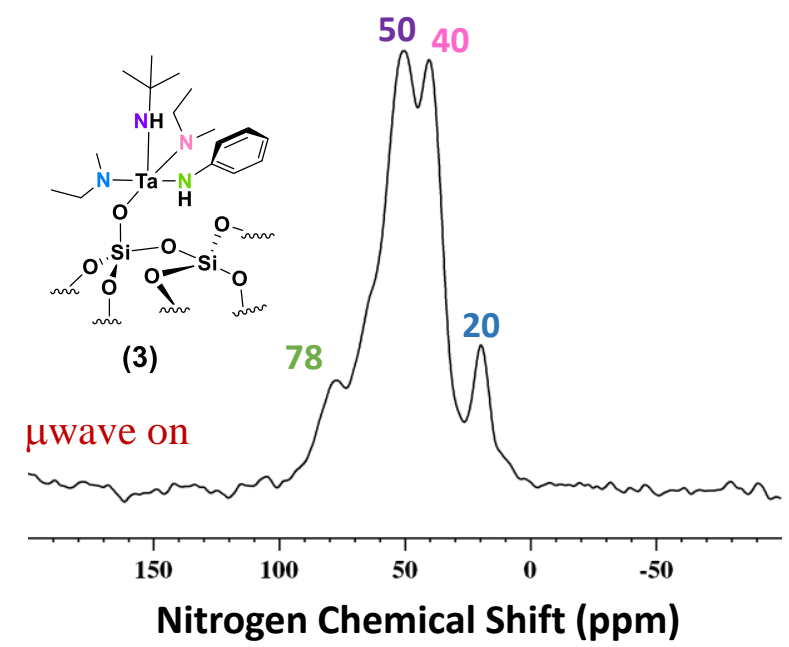

Figure 8. ${ }^{15} \mathrm{~N}$ DNP-SENS of $\left[(\equiv \mathrm{Si}-\mathrm{O}-) \mathrm{Ta}\left(\eta^{1} \sigma-\mathrm{NEtMe}\right)_{2}\left(-\mathrm{NH}^{\mathrm{t}} \mathrm{Bu}\right)(-\right.$ $\left.\mathrm{NHC}_{6} \mathrm{H}_{5}\right] 3$.

The data clearly show that the imido ligand undergoes an exchange with the aniline via a $2+2$ mechanism (forming a metallacyclobutene). Further, they confirm the reactivity of the surface fragment $([\mathrm{M}]=\mathrm{NR})$ in hydroamination, The catalyst facilitates the nucleophilic addition of $\mathrm{N}$-heterocycles onto terminal and internal alkynes through the activation of the triple bond, transforming the electron-rich alkyne into an electrophile. ${ }^{14}$
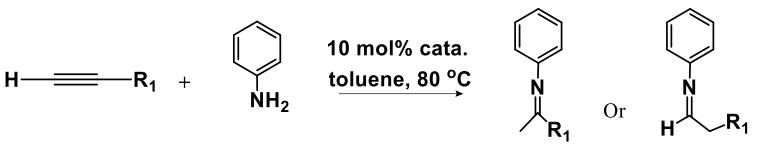

Markovnikov (M) Ani-Markovnikov (AM)

Scheme 1. Hydroamination reaction. ${ }^{16}$

Table 2. Hydroamination of various alkyne-amine combinations catalyzed by $\mathbf{1}$ in a batch reactor.*

\begin{tabular}{cccc} 
Entry & Alkyne & Amine & 6 \\
1 & 1-Decyne & Aniline & 63 \\
2 & 1-Octyne & Aniline & 24 \\
3 & 1-Hexyne & Aniline & 0 \\
4 & Diphenylacetylene & Aniline & 0 \\
6 & 3-Hexyne & Aniline & 0 \\
7 & 2-Pentyn-10l & Aniline & 16 \\
\hline & 1-Octyne & 4-Octyne & 4-chloroaniline
\end{tabular}


*Catalyst $1(10 \mathrm{~mol} \%, 0.03 \mathrm{mmol})$ in degassed toluene $(1 \mathrm{~mL})$, at $80^{\circ} \mathrm{C}$, for $16 \mathrm{~h}$. Cat./alkyne/primary amine $=1 / 1 / 1$, alkyne $(0.03$ $\mathrm{mmol})$, aniline $(0.03 \mathrm{mmol})$. Conversion determined by GC-MS.

The direct addition of amines to $\mathrm{C}-\mathrm{C}$ multiple bonds is difficult thermodynamically. ${ }^{9,13} \mathrm{~A}$ further significant challenge in hydroamination is the repulsion between a nitrogen lone pair and the alkyne $\pi$-electron system, and another is to facilitate regioselectively of the hydroamination of the $\mathrm{C} \equiv \mathrm{C}$ bond toward the Markovnikov or antiMarkovnikov products (Scheme 1). ${ }^{18,22}$

To demonstrate the performance of the hydroamination catalyst and assess how well it meets these challenges, we investigated its performance with various reactant combinations in a batch reactor at $80^{\circ} \mathrm{C}$ for $16 \mathrm{~h}$ (Scheme 2, Table 2). The reactants included with a variety of terminal and internal alkynes. The data (Table 2) show that (a) terminal alkynes react much faster than internal alkynes; (b) a higher conversion was reached with 1-octyne than 1decyne; and (c) aniline reacted much faster than arylamines with various functional groups.

Catalyst $\mathbf{1}$ is active for the hydroamination of functionalized alkynes with several primary amines. Only one product produced, either Markonikov or anti-Markonikov we couldn't define the product observed by GC-MS. Usually aliphatic alkynes leads to anti-markonicov product. ${ }^{14}$ Catalyst $\mathbf{1}$ selectivity directed the reaction towards anti- Markonikov.

To gain insight into the mechanism and the catalyst's selectivity of hydroamination of terminal alkynes catalyzed by the silicasupported tantalum complex, we turned to density functional theory (DFT). To minimize computational costs, all the calculations were done with propyne as a reactant representing terminal alkynes, but no structural simplifications of the aniline substrates were imposed. The catalyst $\left[(\equiv \mathrm{Si}-\mathrm{O}-) \mathrm{Ta}(=\mathrm{NtBu})(\mathrm{NMeEt})_{2}\right]$ was represented with the support represented as a silica cluster of 14 atoms (see SI). This cluster approach has been reported frequently in related mechanistic studies. 23

After investigating multiple scenarios involving the two substrates, we infer that the catalytic cycle reported in Scheme 3 is the most likely under our reaction conditions.

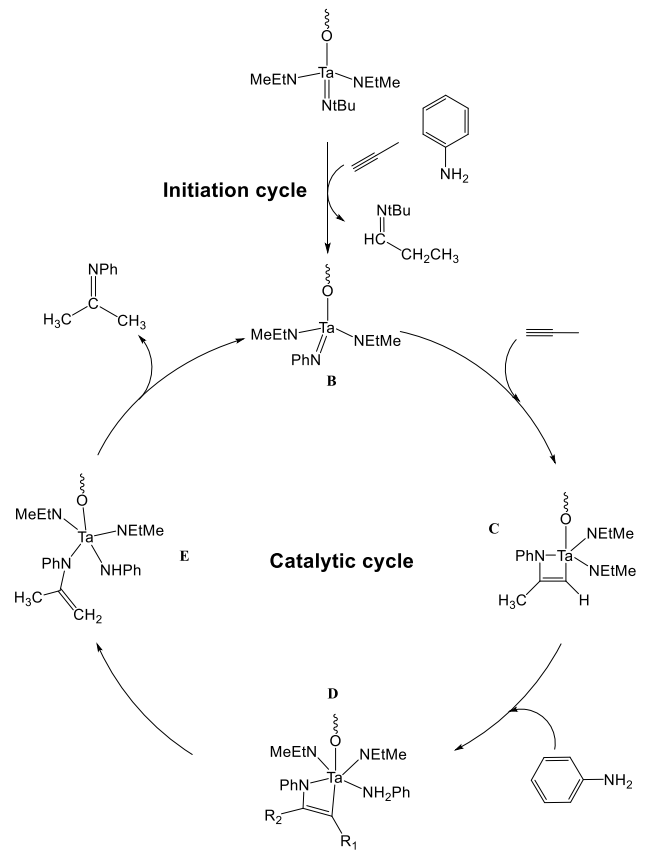

Scheme 3. Catalytic cycle for propyne hydroamination with aniline in presence of the supported tantalum complex catalyst.

After the initiation cycle (see Figure S12 in the SI for the energy profile), the catalytically active species $\mathbf{B}$ is formed. In $\mathbf{B}$ the $=\mathrm{NtBu}$ ligand initially present on the Ta is substituted by a $\mathrm{Ph}$ amido ligand derived from the reaction of aniline during the initiation step (see the SI for details).

Starting from $\mathbf{B}$, the catalytic cycle starts with a $[2+2]$ cycloaddition of the alkyne to the tantalum imido bond, leading to the azametallacyclobutene intermediate $\mathbf{C}$ (isolated intermediate $\mathbf{2}$ ), with no formation of a Ta-alkyne coordination intermediate.

The pathways corresponding to opposite regiochemistry are reported (Figure 9), with the one leading to the Markovnikov product (in red) being favored by $2.3 \mathrm{kcal} / \mathrm{mol}$ in the cycloaddition step (24.1 vs. $26.4 \mathrm{kcal} / \mathrm{mol}$ )

The subsequent coordination of aniline to Ta is slightly endothermic with respect to the azametallacyclobutene but still thermodynamically favored relative to the starting species. The ring-opening step proceeds by a proton transfer from aniline to the carbon bound to the metal (D-E) and requires an energy barrier of 15 $\mathrm{kcal} / \mathrm{mol}$ for the favored pathway shown in red. The resulting enamide amido complex $\mathbf{E}$ is lower in energy by almost $14 \mathrm{kcal} / \mathrm{mol}$ 
relative to the azametallacyclobutene. The final proton transfer from the $\mathrm{Ph}$ amino ligand of $\mathbf{E}$ to the carbon of the enamide group, with a barrier of $23.8 \mathrm{kcal} / \mathrm{mol}$ for the favored pathway, liberates the enamine and regenerates the catalytically active tantalum imido species.
On the basis of these mechanistic results, we infer that the catalytic cycle emerges as regioselective towards the formation of the Markovnikov product with the selection occurring in the cycloaddition step.

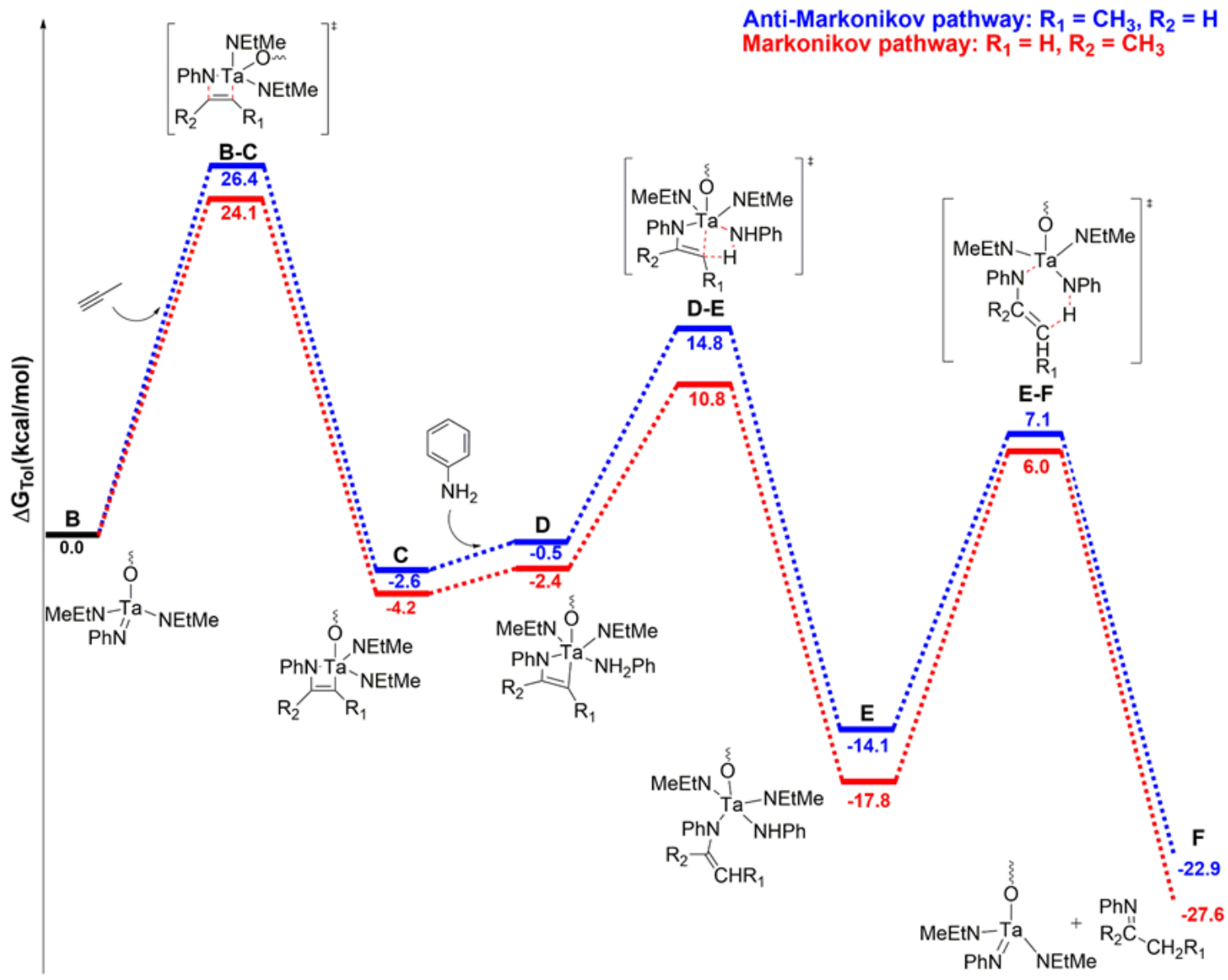

Figure 9. Energy profile for propyne hydroamination with aniline in the presence of tantalum imido catalyst. Free energies (in kcal/mol) are given for the species in toluene.

The two competing cycloaddition transition states (TSs) are reported (Figure 10).

\section{$\{2+2\}$ cycloaddition TS}

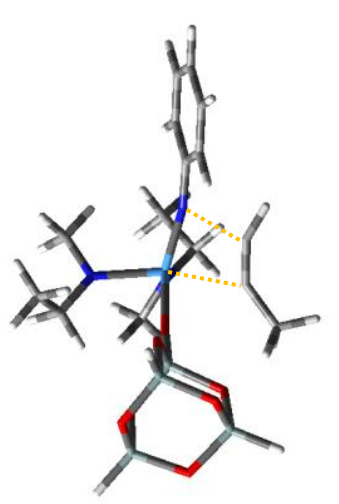

Anti-Markovnikov pathway

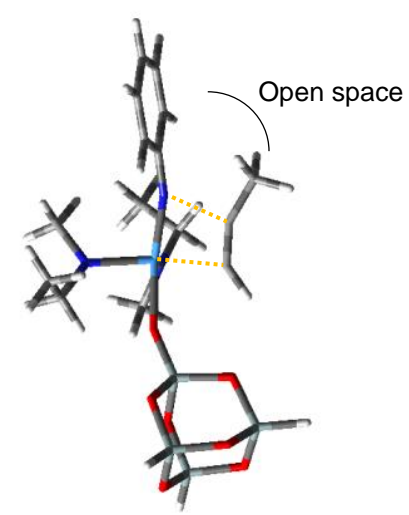

Markovnikov pathway

Figure 10. Optimized geometries for the cycloaddition transition state (B-C). The $\mathrm{Si}$ atoms are shown in teal, $\mathrm{H}$ in white, $\mathrm{C}$ in gray, $\mathrm{N}$ in blue, Ta in sky-blue, and $\mathrm{O}$ in red.

The steric hindrance of the metal environment seems to play a key role in the regioselection of the product associated with repulsive interactions with the substituent group on the alkyne (methyl in our model). In the catalytic cycle, the alkyne substituent is easily hosted behind the flat phenyl group on the imido ligand away from the support in the favored cycloaddition TS. In contrast, in the TS that would lead to the anti-Markovnikov product, the complex is slightly distorted to avoid the clash between the support and the alkyne substituent with the alkyne carbon atoms ending up at shorter distances from the NMeEt ligand (3.5-3.6 $\AA$ ). In contrast, in the initiation cycle, the catalyst bears a more hindered tBu group on the imido ligand that ends up clashing with the alkyne, favoring the opposite regioselectivity (see Figure S12 in the SI).

This evidence, we posit, can be used as a basis for fine-tuning the substituenats so that steric hindrance will facilitate selective catalysis to make one regioisomer product.

\section{ASSOCIATED CONTENT}


Supporting Information

The Supporting Information is available free of charge on the ACS Publications website at DOI:

Elemental analysis, NMR Characterization, and products analysis.

EXAF data analysis details.

\section{AUTHOR INFORMATION}

Corresponding Author

*Email: luigi.cavallo@kaust.edu.sa , bcgates@ucdavis.edu, and jeanmarie.basset@kaust.edu.sa

\section{Notes}

The authors declare no competing financial interests.

\section{ACKNOWLEDGMENT}

The research was supported by the King Abdullah University of Science and Technology (KAUST). The authors acknowledge EdyAbou-Hamad, Abdul-Hamid Emwas, and Andrei Gurinov for their assistance for NMR measurements. The work at the University of California was supported by the U.S. Department of Energy, Office of Science, Basic Energy Sciences (DE-FG02-04ER15513). We acknowledge the European Synchrotron Radiation Facility for provision of synchrotron radiation facilities and thank Antonio Aguilar for assistance in using beamline BM30 B.

\section{REFERENCES}

(1) Pelletier, J. r. m. D.; Basset, J.-M., Catalysis by Design: Well-Defined Single-Site Heterogeneous Catalysts, Accounts of chemical research 2016, 49, 664-677.

(2) Basset, J.-M.; Psaro, R.; Roberto, D.; Ugo, R., Modern surface organometallic chemistry. John Wiley \& Sons: 2009;

(3) Sun, M.; Zhang, J.; Putaj, P.; Caps, V.; Lefebvre, F. d. r.; Pelletier, J.; Basset, J.-M., Catalytic oxidation of light alkanes $(\mathrm{C} 1-\mathrm{C} 4)$ by heteropoly compounds, Chemical reviews 2013, 114, 981-1019.

(4) Vidal, V.; Théolier, A.; Thivolle-Cazat, J.; Basset, J.-M., Metathesis of Alkanes Catalyzed by Silica-Supported Transition Metal Hydrides, Science 1997, 276, 99-102.

(5) Azofra, L. M.; Morlanés, N.; Poater, A.; Samantaray, M. K.; Vidjayacoumar, B.; Albahily, K.; Cavallo, L.; Basset, J. M., Single-Site Molybdenum on Solid Support Materials for Catalytic Hydrogenation of N2-into-NH3, Angewandte Chemie 2018, 130, 16038-16042.

(6) Barman, S.; Merle, N.; Minenkov, Y.; De Mallmann, A.; Samantaray, M. K.; Le Quéméner, F.; Szeto, K. C.; Abou-Hamad, E.; Cavallo, L.; Taoufik, M.; Basset, J.-M., Well-Defined Silica Grafted Molybdenum Bis(imido) Catalysts for
Imine Metathesis Reactions, Organometallics 2017, 36, 1550-1556.

(7) Hamzaoui, B.; Pelletier, J. D.; Abou-Hamad, E.; Basset, J.-M., Well-defined silica-supported zirconium-imido complexes mediated heterogeneous imine metathesis, Chemical Communications 2016, 52, 4617-4620.

(8) Aljuhani, M. A.; Barman, S.; Abou-Hamad, E.; Gurinov, A.; Ould-Chikh, S.; Guan, E.; Jedidi, A.; Cavallo, L.; Gates, B. C.; Pelletier, J. D. A.; Basset, J.-M., Imine Metathesis Catalyzed by a Silica-Supported Hafnium Imido Complex, $A C S$ Catalysis 2018, 9440-9446.

(9) Pohlki, F.; Doye, S., The catalytic hydroamination of alkynes, Chemical Society Reviews 2003, 32, 104-114.

(10) Muller, T. E.; Hultzsch, K. C.; Yus, M.; Foubelo, F.; Tada, M., Hydroamination: direct addition of amines to alkenes and alkynes, Chemical reviews 2008, 108, 3795-3892.

(11) Alayrac, C.; Berkenbusch, T.; Breit, B.; Ditrich, K., Science of Synthesis: Houben-Weyl Methods of Molecular Transformations Vol. 25: Aldehydes. Georg Thieme Verlag: 2014;

(12) Lui, E. K. J.; Brandt, J. W.; Schafer, L. L., Regio- and Stereoselective Hydroamination of Alkynes Using an Ammonia Surrogate: Synthesis of N-Silylenamines as Reactive Synthons, Journal of the American Chemical Society 2018, 140, 4973-4976.

(13) Patel, M.; Saunthwal, R. K.; Verma, A. K., Base-Mediated Hydroamination of Alkynes, Accounts of Chemical Research 2017, 50, 240254.

(14) Shi, S.-L.; Buchwald, S. L., Copper-catalysed selective hydroamination reactions of alkynes, Nature Chemistry 2014, 7, 38.

(15) Huang, L.; Arndt, M.; Gooßen, K.; Heydt, H.; Gooßen, L. J., Late Transition Metal-Catalyzed Hydroamination and Hydroamidation, Chemical Reviews 2015, 115, 2596-2697.

(16) Severin, R.; Doye, S., The catalytic hydroamination of alkynes, Chemical Society Reviews 2007, 36, 1407-1420.

(17) Müller, T. E.; Hultzsch, K. C.; Yus, M.; Foubelo, F.; Tada, M., Hydroamination: Direct Addition of Amines to Alkenes and Alkynes, Chemical Reviews 2008, 108, 3795-3892.

(18) Jimenez, O.; Müller, T. E.; Sievers, C.; Spirkl, A.; Lercher, J. A., Markownikoff and antiMarkownikoff hydroamination with palladium 
catalysts immobilized in thin films of silica supported ionic liquids, Chemical communications 2006, 2974-2976.

(19) Cook, A. K.; Copéret, C., Alkyne Hydroamination Catalyzed by Silica-Supported Isolated Zn(II) Sites, Organometallics 2018, 37, 1342-1345.

(20) Hamzaoui, B.; Pelletier, J. D. A.; AbouHamad, E.; Basset, J.-M., Well-defined silicasupported zirconium-imido complexes mediated heterogeneous imine metathesis, Chemical Communications 2016, 52, 4617-4620.

(21) Copéret, C.; Chabanas, M.; Petroff SaintArroman, R.; Basset, J. M., Homogeneous and heterogeneous catalysis: bridging the gap through surface organometallic chemistry, Angewandte Chemie International Edition 2003, 42, 156-181. (22) Tillack, A.; Garcia Castro, I.; Hartung, C. G.; Beller, M., Anti-Markovnikov Hydroamination of Terminal Alkynes, Angewandte Chemie International Edition 2002, 41, 2541-2543.

(23) Maity, N.; Barman, S.; Callens, E.; Samantaray, M. K.; Abou-Hamad, E.; Minenkov, Y.; D'Elia, V.; Hoffman, A. S.; Widdifield, C. M.; Cavallo, L.; Gates, B. C.; Basset, J.-M., Controlling the hydrogenolysis of silica-supported tungsten pentamethyl leads to a class of highly electron deficient partially alkylated metal hydrides, Chemical Science 2016, 7, 1558-1568. 


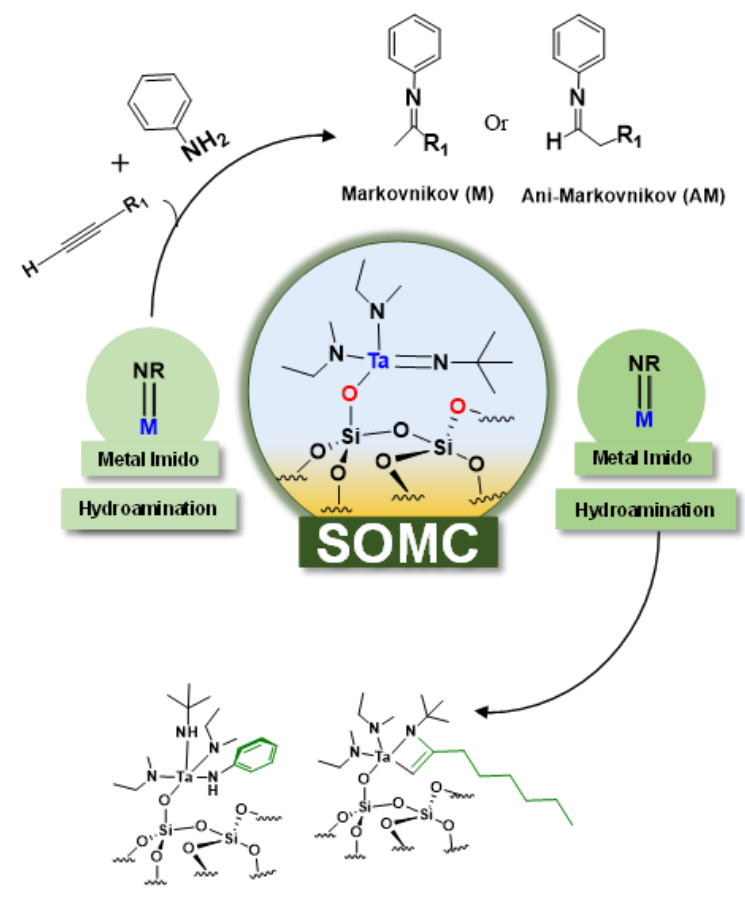

